\title{
Potential prevention effects of Rubus occidentalis seed on UVB-induced MMP-1 production and procollagen degradation in CCD-986sk cells
}

\author{
Dong-Hee Kim ${ }^{1}$ Tae-Soon Park ${ }^{1} \cdot$ Jun-Ho Son ${ }^{1}$ (D
}

Received: 6 July 2016 / Accepted: 31 August 2016 / Published Online: 31 December 2016

(C) The Korean Society for Applied Biological Chemistry 2016

\begin{abstract}
UV exposure induces matrix metalloproteinases (MMPs) and extracellular matrix-degrading enzymes expression. We studied the protective effect of Rubus occidentalis seed against UVB-generated skin photoaging using human fibroblast cells (CCD-986sk). We used an ELISA kit to measure the supernatents of procollagen type I and MMP-1 in CCD-986sk cells after they were exposed to UVB irradiation. The CCD-986sk cells that were used with RC-E/E after the UVB irradiation caused higher levels of type I procollagen and lesser levels of MMP-1 compared with the control group. Furthermore, the RC-E/E treated group showed lesser MMP-1 levels and higher procollagen type I levels than the untreated counterpart. Therefore, it can be concluded that Rubus occidentalis seed can prevent from skin photoaging.
\end{abstract}

Keywords Anti-wrinkle C CCD-986sk · MMP-1 · Procollagen · Rubus occidentalis seed

\section{Introduction}

The skin aging process consists of theintrinsic (chronologic) aging thatinternal organs and the extrinsic (photoaging) aging that isinduced by exposure to environmental factors. Exposure to ultraviolet (UV) irradiation from the sun causes extrinsic aging, which can induce photoaging (Bae et al. 2008); however,

Jun-Ho Son $(\bowtie)$

E-mail: bio115@nikom.or.kr

${ }^{1}$ Traditional Korean Medicine Technology Division R\&D Department Applied Product Development Team, National Development Institute of Korean Medicine, Gyeongbuk38540, Republicof Korea

This is an Open Access article distributed under the terms of the Creative Commons Attribution Non-Commercial License (http://creativecommons. org/licenses/by-nc/3.0/) which permits unrestricted non-commercial use, distribution, and reproduction in any medium, provided the original work is properly cited. photoaging is mainly due to UVB irradiation exposureand is characterized by an altered pigmentation, inflammation and collagen degradation (Bennett 2008; Ahn et al. 2013). Chronic exposure of skin to UVB irradiation also causes the production of matrix metalloproteinases (MMPs), resulting in the alteration of collagenous skin tissues (Ahn et al. 2013). MMPs are a family of extracellular matrix (ECM)-degenerating enzymes and are generated from different types of cells including fibroblasts and endothelial cells, as well as immune cells. MMPs play a key role in the dynamic remodeling of the ECM and are comprised of functional subclassified groups including membrane-type MMPs, and other nonclassified MMPs (Visse and Nagase 2003); in particular, collagenase-1 (MMP-1) production is significantly enhanced in late passage skin fibroblasts (Tsuji et al. 2001; Tsukahara et al. 2001; Varani et al. 2002; Brennan et al. 2003). Collagenase can cleave the interstitial collagenases that are found in the skin such as type I collagen (Lee et al. 2008). Type I collagen accounts for 70 to $90 \%$ of total collagen (Kerrigan et al. 2000) and the functional characteristic of skin rely on the preservation of dermal collagen. The metabolic control of type I collagen may therefore be useful for a diversity of cosmetic materials.

The fruits of Rubus occidentalis Miq. (R. occidentalis), a member of the Rosaceae family, have long been used as part of traditional Korean folk medicines to treats asthma and allergic diseases (Shin et al. 2014). Phenolic acid, organic acid, triterpenoids, flavonoids, and ellagitannin are the reported compounds of $R$. occidentalis Miq. fruits (Ju et al. 2009). The fruits are mostly used to make traditional wine through the fermentation and maturation of perfectly matured fruits that are harvested in June and July; therefore, we especially focused on the usage of wine-processing leftovers. The $R$. occidentalis seed, which is rich in unsaturated fatty acids and $\alpha$-linoleic acids, is used in S. Korea for the prevention of gingivitis, rashes, eczema, and other skin lesions (Pourrat et al. 1973). We determined the effects of R. occidentalis seed on UVB-induced MMP-1 production levels and type I procollagen contents in humanskin fibroblast (CCD-986sk) cells. 


\section{Materials and Methods}

\section{Materials}

All of the cell-culture reagents that were used in the present study were obtained from Gibco BRL Co. (Rockville, NE, USA), while 3-[4,5-dimethylthylthiazol]-2yl]-2,5-diphenyl-tetrazoliumbromide (MTT) was obtained from Sigma Chemical Co. (St. Louis, MO, USA). The productions of MMP-1 (Abcam, Cambridge, MA, USA) and type I procollagen (Takara Co., Otsu, Japan) were measured using commercial ELISA- and EIA-kit antibodies, and the MMP-1 and type I procollagen were purchased from Santa Cruz (Santa Cruz, CA, USA).

\section{Preparation of $\boldsymbol{R}$. occidentalis seeds extract}

The $R$. occidentalis seeds were obtained from the "Sam do bong Farm" company that is located in Kimcheon, Gyeongbuk, Korea. A $100 \mathrm{~g}$ of the $R$. occidentalis seed was measured and the seeds were soaked in $70 \%$ ethyl alcohol $(\mathrm{EtOH})$ for $24 \mathrm{~h}$ at room temperature (RT). The mixture was filtered with Whatman No. 2 (Sigma Chemical Co.) and the procedure was repeated two more times. The total extract was then evaporated and $5.4 \mathrm{~g}$ of EtOH extract was obtained. The aqueous phase of EtOH extract was suspended again, mixed with an same volume of n-hexane, and separated by a separating funnel. A hexane extract was evaporated and $0.5 \mathrm{mg}$ was obtained. These procedures were repeated with other solventsethyl acetate (EtOAc) and butyl alcohol $(\mathrm{BuOH})$ sequentially. In terms of powder samples, $0.8,1.4$, and $2.0 \mathrm{~g}$ were obtained from the EtOAc, $\mathrm{BuOH}$, and final aqueous layer, respectively.

\section{Cell culture}

After the CCD-986sk human skin fibroblast cell line was got from the American Type Culture Collection ATCC (Manassas, VA, USA), it was commonly cultured in a Dulbecco's modified Eagle medium (Hyclone Laboratories, Logan, UT, USA) added with 10 $\%(\mathrm{v} / \mathrm{v})$ FBS and $1 \%(\mathrm{v} / \mathrm{v})$ penicillin-streptomycin, while under $37{ }^{\circ} \mathrm{C}$ in an incubator with a humidified atmosphere of $5 \% \mathrm{CO}_{2}$.

\section{Determination of cell viability}

The cell toxicity of the $R$. occidentalis seeds extract (RCE) and RCE fractions were determined by measuring the reduction of tetrazolium in accordance with a modified version of Shin et al.'s protocol (Shin et al. 2014). Briefly, the cells were seeded at a consistensy of $5 \times 10^{3}$ cells/well in 96-well plates. After $24 \mathrm{~h}$ storage, the CCD-986sk cell was exposed to UVB for $20 \mathrm{~mJ} / \mathrm{cm}^{2}$, followed by indicated concentrations of the RCE; then, $10 \mu \mathrm{L}$ of the extract was added to the fibroblast cells while the equal volume of dilution solution was added to the control. After $48 \mathrm{~h}$ of incubation, MTT solution $(5 \mathrm{mg} / \mathrm{mL})$ was added to $4 \mathrm{~h}$ incubation period. After the MTT solution was removed, $100 \mu \mathrm{L}$ of DMSO was added followed by a further $10 \mathrm{~min}$ incubation period. The wavelength was set at $540 \mathrm{~nm}$ and the cell toxicity was measured using the Sunrise ELISA plate reader (Tecan Austria GmBH, Grödig/Salzburg, Austria).

\section{MMP-1 inhibition and type I procollagen synthesis assay}

The cells were seeded at a consistency of $5 \times 10^{4}$ in 12 -well plates and, after $24 \mathrm{~h}$ of incubation, they were treated with the RCE and $\mathrm{RCE}$ fractions for $48 \mathrm{~h}$. To determine the production levels of the MMP-land type I procollagen, the medium was measured using commercially available ELISA kits in accordance with the manufacture's instructions (Abcam and Takara). The absorbances were measured at $450 \mathrm{~nm}$ measuring an ELISA plate reader.

\section{cDNA synthesis and RT-PCR}

The cells were incubated in the RCE-E treatment for $48 \mathrm{~h}$. The total RNA was extracted using Trizol (Invitrogen, Carlsbad, CA, USA) following themanufacture's directions. Two $\mu \mathrm{g}$ of RNA were used for the $1 \mathrm{~h}$ cDNA synthesis that involved the use of oligo (dT) primer and reverse transcriptase (Promega, WI, USA) at $42{ }^{\circ} \mathrm{C}$. A PCR was performed with the cDNA to analyze the transcript expressions of MMP-1, MMP-2, and MMP-3, where by a $55{ }^{\circ} \mathrm{C}$ annealing temperature was applied for $30 \mathrm{sec}$ and $72{ }^{\circ} \mathrm{C}$ was applied for a $1 \mathrm{~min}$ extension; the total for the PCR is 30 cycles. The transcripts were separated in a $1.5 \%$ agarose gel and stained with Redsafe (iNtRON Biotechnology Inc., Sungnam, Gyeonggi, Korea), followed by the use of a LAS4000 (Fujifilm, Tokyo, Japan) image analyzer for the confirmation.

\section{Western blot analysis}

Shotly, the cells were seeded in $100 \mathrm{~mm}$ culture dish and grown for $24 \mathrm{~h}$, followed byRCE-E treatment for $48 \mathrm{~h}$.After the RCE-E treatment, the cells were, then, washed twice with cold PBS and lysed for $5 \mathrm{~min}$ on ice in a $1 \mathrm{~mL}$ buffer of radio immunoprecipitation assay with protease inhibitor cocktails $(100 \mathrm{X})$. The lysates were clarified by centrifugation at $12,000 \mathrm{rpm}$ for $20 \mathrm{~min}$ at $4{ }^{\circ} \mathrm{C}$, and the total protein concentrations were measured using a BSA kit. A western blot analysis was conducted to investigate the protein expressions of MMP-1 and type I collagen. First, 15 $\mu \mathrm{g}$ of each protein was separated using $10 \%$ sodium dodecyl sulfate polyacrylamide gel electrophoresis and they were then transferred onto PVDF membranes; the membranes were incubated for $1 \mathrm{~h}$ in $5 \%$ skim milk with TBST followed by their incubation with the designated primary antibodies (1:1000) the membranes were then washed and incubated with secondary HRP-labeled antibodies (1:1000) for $2 \mathrm{~h}$ at RT. Chemiluminescent images of the blots were detected using the SuperSignal West Pico chemiluminescent substrate (Pierce, Rockford, IL, USA) under an LAS 4000 image analyzer (Fuji Film Life Science, Tokyo, Japan). The membranes were then stripped and reprobed with $\beta$-actin antibody serving as the loading control.

\section{Data analysis}

This study was conducted in triplicate. An analysis of variance 
was run using the raw data, and the mean values and standard deviations were analyzed using the ANOVA system. Differences among the means were determined by a $t$-test, and significance occurs at $* p<0.05$ and ${ }^{* *} p<0.005$.

\section{Results and Discussion}

\section{Effects of RCE on cell viability of UVB-induced CCD-986sk cells}

Before investigating the preventive effect of the RCE and RCEfractions on UVB-induced MMP-1 production and type I procollagen decline, we first verified the cytotoxicity ofthe RCE in the CCD986sk cells using an MTT assay.Result in Fig. 1, the cells were treated with indicated concentrations of the RCE and RCEfractions; the extract did not show any toxic effects up to $20 \mu \mathrm{g}$ / $\mathrm{mL}$. For the investigation of the effect of RCE on UVB-induced MMP-1 production and type I pro-collagen decline, we used concentrations between 5 and $20 \mu \mathrm{g} / \mathrm{mL}$ in the subsequent experiments.

\section{Effect of RCE on MMP-1 inhibition and type I pro-collagen synthesis}

MMPs are directly responsible enzymes for the degradation of ECM components, and they specifically denatured collagens (Kim et al. 2011) therefore, UV irradiation degrades ECM by increasing the MMPs production in the skin. We demonstrated the effects of the RCE and RCE-fractions on UVB-induced MMP-1 expression in CCD-986sk cells (Fig. 2). The cells were treated with 5, 10 and $20 \mu \mathrm{g} / \mathrm{mL}$ concentrations of RCE and RCE-fractionsfor $48 \mathrm{~h}$ and the MMP-1 concentration was determined usingan ELISA kit.
The RCE and RCE-fractions suppressed MMP-1 expression inthose cells exposed to UVB; in particular, the RC-E/Efraction reduced MMP-1 expression by $12 \%$ at $5 \mu \mathrm{g} / \mathrm{mL}$ and $22 \%$ at 10 $\mu \mathrm{g} / \mathrm{mL}$. The highest concentration of the RC-E/E fraction prevented the expression of MMP-1up to $50 \%$ in a dose-dependent manner. Previous reports have shown that UVB exposure stimulates collagen degradation and the inhibition of type I procollagen production in fibroblasts (Fisher et al. 1996) therefore, we investigated the protective effect of the RCE extracts against UVB. As shown in Fig. 3, the extract of RC-E/E significantly increased type I procollagen synthesis with restorations of 8 and $17 \%$ at 10 and $20 \mu \mathrm{g} / \mathrm{mL}$, respectively. Overall, the RC-E/E extract suppressed the expressions of UVB-induced MMP-1 and type I collagen protein in the human fibroblast cell (CCD-986sk).

RCE decreased expressions of type I procollagen and inhibition of MMP-1 protein in CCD-986sk cells

We next examined the effects of the RC-E/E fraction on the decrease of type I procollagen and the increase of MMP-1 protein that are induced by UV. As depicted in Fig. 4, the reductions of the expressions of type I procollagen and inhibition of MMP-1 protein were significantly induced at $48 \mathrm{~h}$ in those fibroblasts exposed to UVB, as expected. Pretreatment with the RC-E/E extract significantly restored the suppuration of the type I procollagen protein expression and also inhibited MMP-1 protein expression in those fibroblasts exposed to UVB, there by showing a pattern alike to the regulation of mRNA expression. All of these results suggest that $\mathrm{RC}-\mathrm{E} / \mathrm{E}$ pretreatment prevents $\mathrm{UV}$-induced changes of type I procollagen and MMP-1 expression at the transcriptional level.

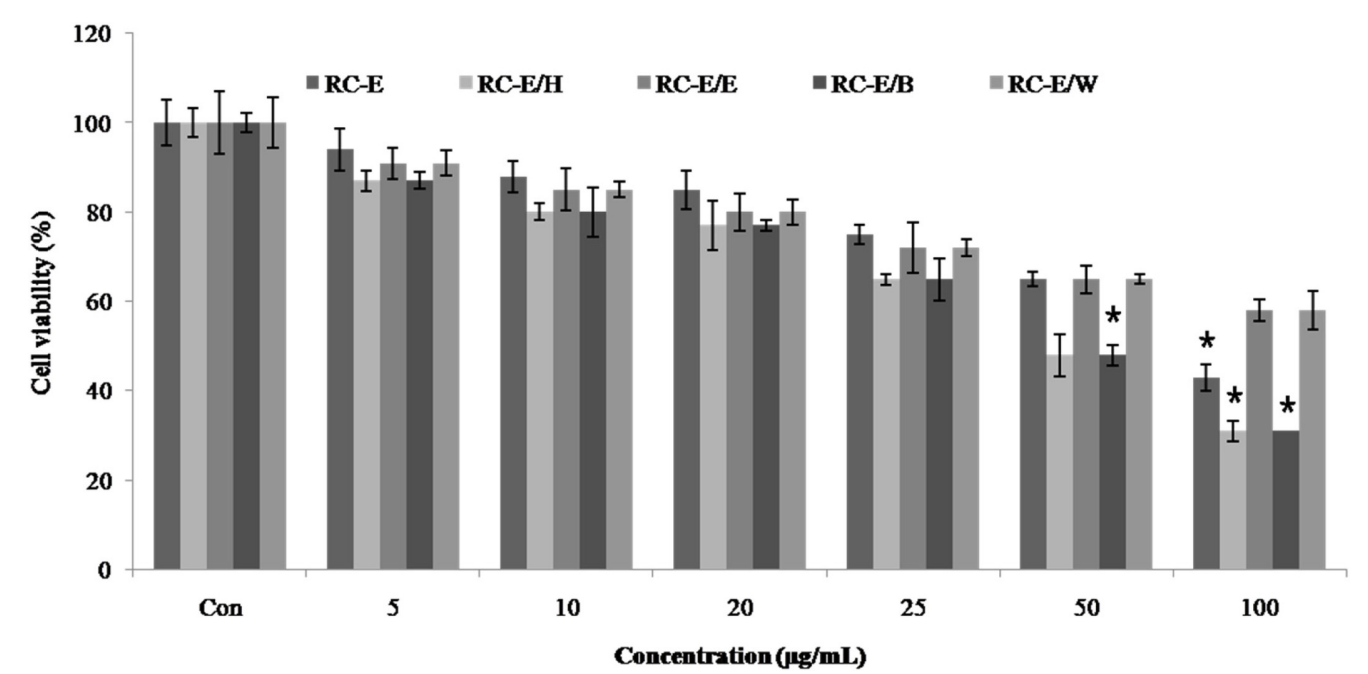

Fig. 1 Cell viability of fibroblast CCD-986sk cells after treatment with Rubus occidentalis-seed extract. The fibroblast cells were exposed to UVB for $20 \mathrm{~mJ} / \mathrm{cm}^{2}$ and treated with varying concentrations of $70 \% \mathrm{EtOH}$ and fraction extracts obtained from the R. occidentalisseed. Cell viability was measured using an MTT assay. Error bar indicates average mean of triple replicates. RC-E: $70 \%$ EtOH extracts; RC-E/H: Hexane fraction of $R$. occidentalis-seed extracts, RC-E/E: Ethyl acetate fraction of $R$. occidentalis-seed extracts; RC-E/B: Butanol fraction of $R$. occidentalis-seed extracts; RC-E/W: Water fraction of $R$. occidentalis-seed extracts 


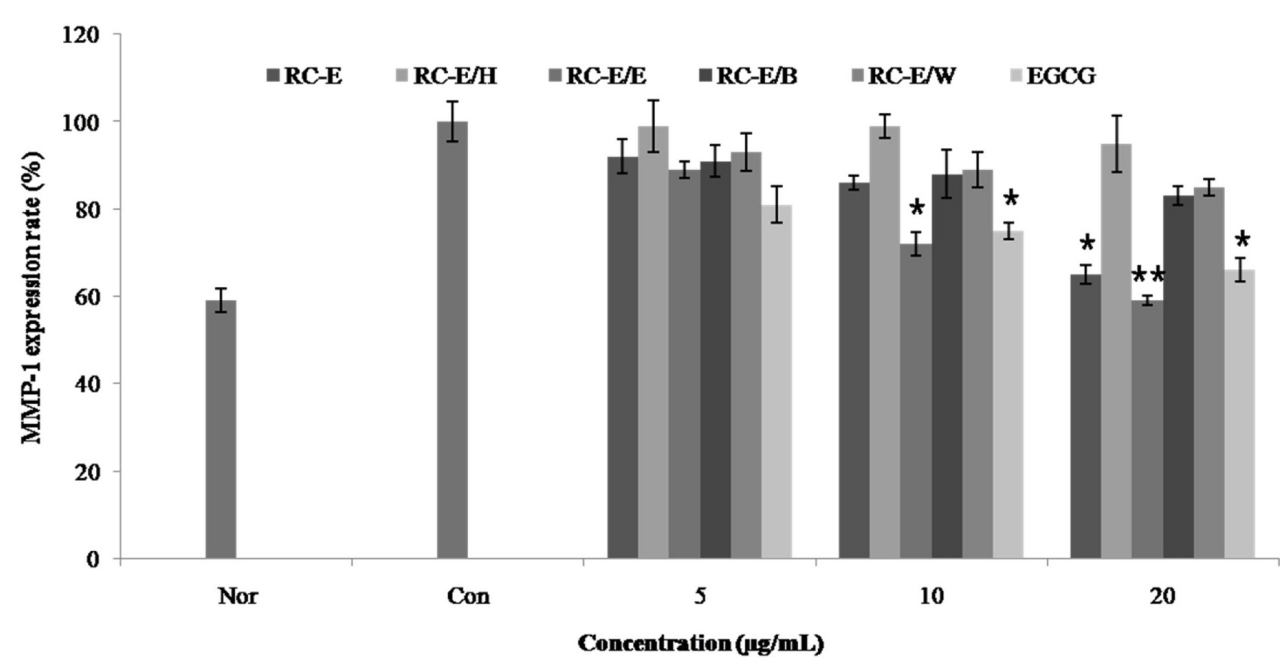

Fig. 2 Inhibition of MMP-1 expression of CCD-986sk fibroblast cells after treatment with $R$. occidentalis-seed extract. Fibroblast cells were exposed to UVB for $20 \mathrm{~mJ} / \mathrm{cm}^{2}$, and were then treated with varying concentrations of $70 \% \mathrm{EtOH}$ and fraction extracts obtained from the $R$. occidentalis-seed. MMP-1 expression was measured using an ELISA kit. Error bar indicates average mean of triple replicates. RC-E: 70 \% EtOH extracts; RC-E/H: Hexane fraction of $R$. occidentalis-seed extracts, RC-E/E: Ethyl acetate fraction of $R$. occidentalis-seed extracts; RC-E/B: Butanol fraction of $R$. occidentalis-seed extracts; RC-E/W: Water fraction of $R$. occidentalis-seed extracts

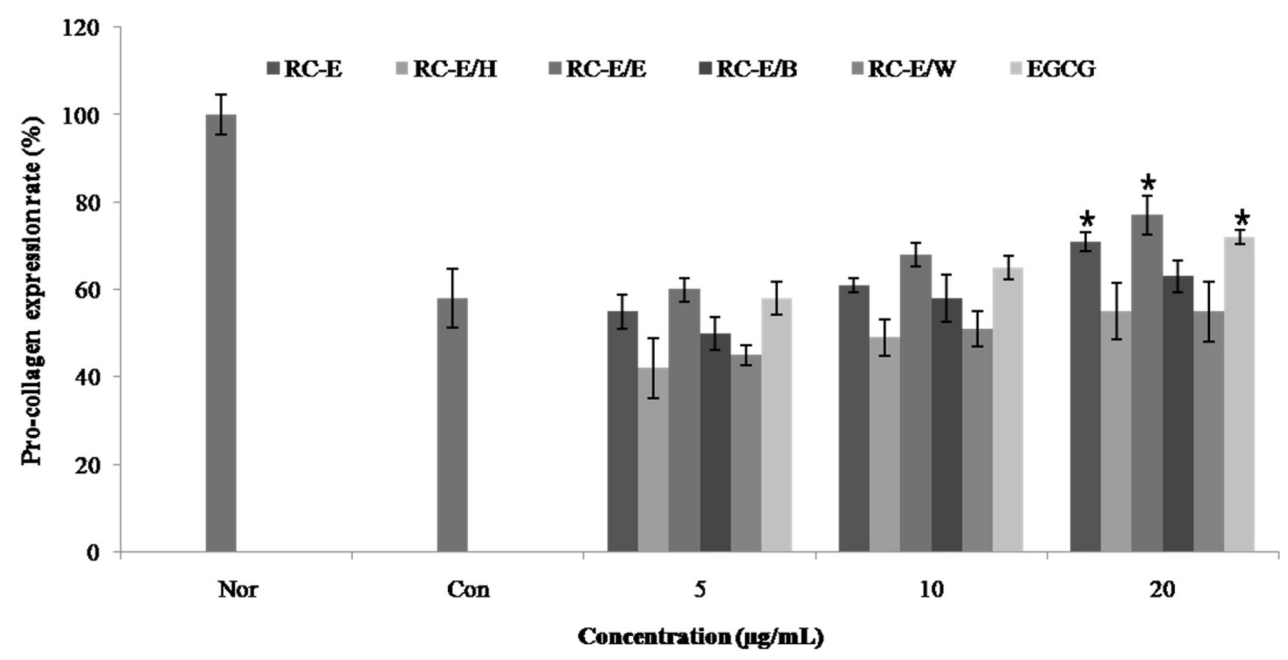

Fig. 3 Inhibition of pro-collagen expression of CCD-986sk fibroblast cells after treatment with R.occidentalis-seed extract. Fibroblast cells were exposed to UVB for $20 \mathrm{~mJ} / \mathrm{cm}^{2}$, and were then treated with varying concentrations of $70 \% \mathrm{EtOH}$ and fraction extracts obtained from the $R$. occidentalis-seed. Procollagen expression was measured using an EIA kit. Error bar indicates average mean of triple replicates. RC-E: $70 \%$ EtOH extracts; RC-E/H: Hexane fraction of $R$. occidentalis-seed extracts, RC-E/E: Ethyl acetate fraction of $R$. occidentalis-seed extracts; RC-E/B: Butanol fraction of R. occidentalis-seed extracts; RC-E/W: Water fraction of $R$. occidentalis-seed extracts

Preventive effects of the RC-E/E on UVB-suppressed type Iprocollagen and MMP-1 mRNA expression

When epidermis of human and experimental animal is penetrated by UVB wavelengths it induces photoaging (Debacq-Chainiaux et al. 2005). In addition, UVB irradiation decreases type I procollagen synthesis rate in human fibroblasts. It has also been reported that UVB irradiation leads to the activation of MMP expression and collagen degradation in the human dermis (Chen et al. 2011). We therefore confirmed in our study that UVB exposure promotes the induction of MMP-1 mRNA expression and the inhibition of type
I procollagen mRNA expression in CCD-986sk cells. To determine the protective effect of RC-E/E on MMP-1 and type I procollagen mRNA expression, the mRNA level was measured by the RT-PCR, as described in manufacture's manual. As shown in Fig. 5, the UVB-induced increased mRNA level of MMP-1 was inhibited by the RC-E/E in a dose-dependent manner. Further, we also confirmed the effect of the RC-E/Eon UVB-reduced type Iprocollagen expression, identifying that the $\mathrm{RC}-\mathrm{E} / \mathrm{E}$ restored the contraction of type Iprocollagen that is caused by UVB exposure. These data suggest that the RC-E/E prevents MMP-1 mRNA 

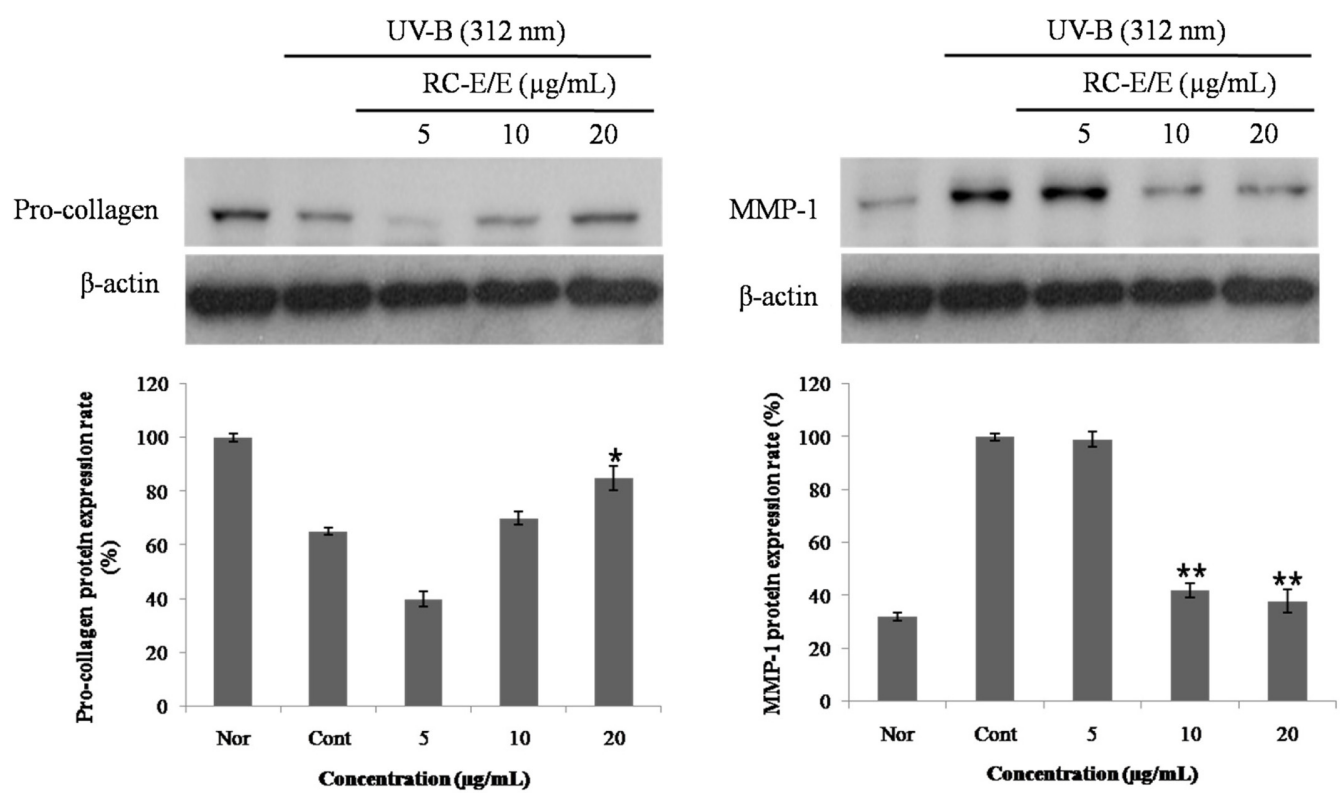

Fig. 4 Expressions of MMP-1 and type I procollagen evaluated by protein level in CCD-986sk fibroblasts after EtOAc-fraction treatment. CCD-986sk cells $\left(5 \times 10^{4}\right)$ were grown and exposed to UVB for $20 \mathrm{~mJ} / \mathrm{cm}^{2}$; the cells were then subject to 5,10 and $20 \mu \mathrm{g} / \mathrm{mL}$ of the EtOAc-fraction treatment. The mRNA levels were normalized using Image Quant software.
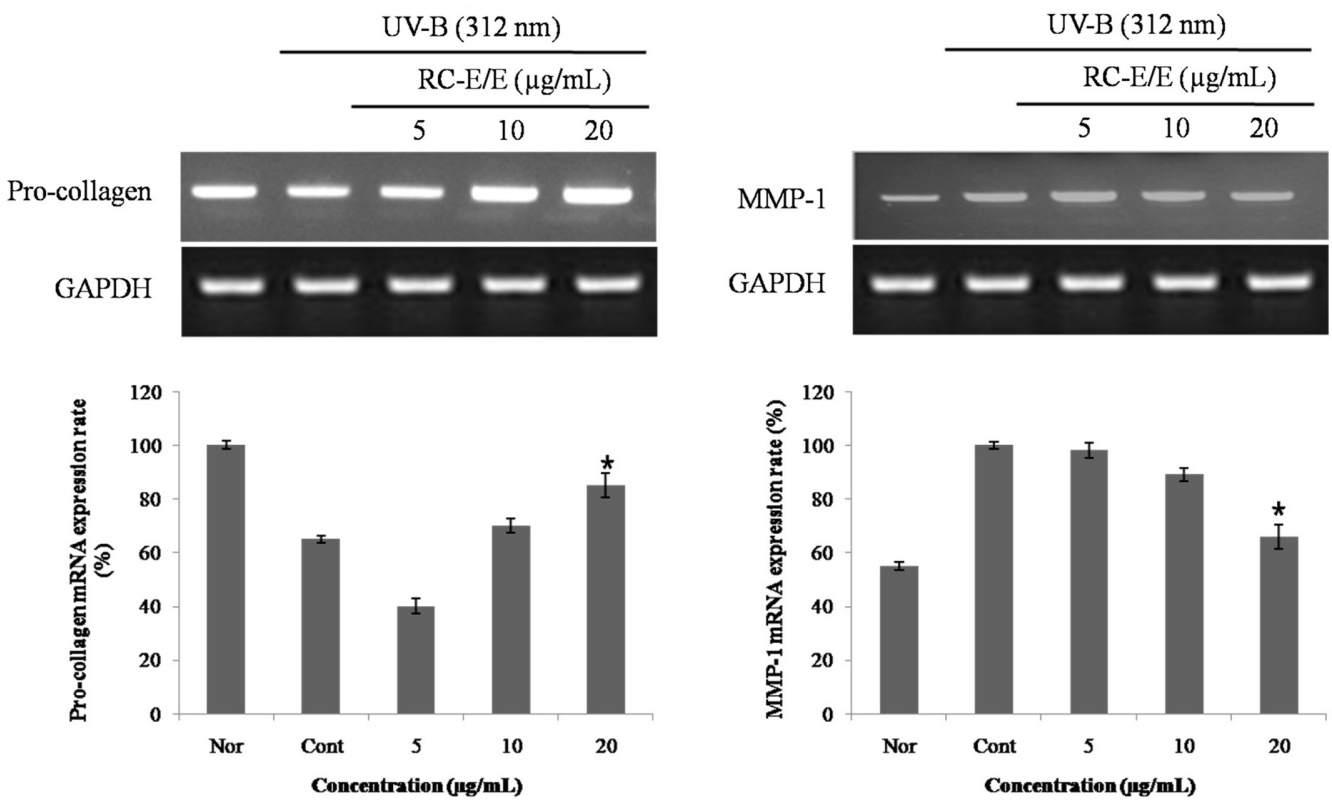

Fig. 5 Expression of MMP-1 and type I procollagen evaluated by mRNA level in CCD-986sk fibroblasts after EtOAc-fraction treatment. The CCD986sk cells $\left(5 \times 10^{4}\right)$ were grown and exposed to UVB for $20 \mathrm{~mJ} / \mathrm{cm}^{2}$; the cells were then subject to 5,10 and $20 \mu \mathrm{g} / \mathrm{mL}$ of EtOAc-fraction treatment. The protein levels were normalized using Image Quant software.

expression and the reduction of UVB-induced type I procollagen mRNA expressionin CCD-986sk cells. The effects of the RC-E/ Efractionon UVB stimulated MMP-1 production and type I procollagen degradation in the CCD-986sk cells.

\section{References}

Ahn BN, Kim JA, Kong CS, Seo Y, Kim SK (2013) Photo protective effect of libanoridin isolated from Corydalis heterocarpa on UVB stressed human keratinocyte cells. Exp Dermatol 22: 155-157 
Bae JY, Choi JS, Choi YJ, Shin SY, Kang SW, Han SJ, Kang YH (2008) (-) Epigallocatechin gallate hampers collagen destruction and collagenase activation in ultraviolet-B-irradiated human dermal fibroblasts: involvement of mitogen-activated protein kinase. Food Chem Toxicol 46: 1298-1307

Bennett DC (2008) Ultraviolet wavebands and melanoma initiation. Pigm Cell Melanoma Res 21: 520-524

Brennan M, Bhatti H, Nerusu KC, Bhagavathula N, Kang S, Fisher GJ, Varani J, Voorhees JJ (2003) Matrix metalloproteinase-1 is the major collagenolytic enzyme responsible for collagen damage in UV-irradiated human skin. Photochem Photobiol 78: 43-48

Chen CL, Liou SF, Chen SJ, Shih MF (2011) Protective effects of Chlorelladerived peptide on UVB-induced production of MMP-1 and degradation of procollagen genes in human skin fibroblasts. Regul Toxicol Pharmacol 60:112-119

Debacq-Chainiaux F, Borlon C, Pascal T, Royer V, Eliaers F, Ninane N, Carrard G, Friguet B, de Longueville F, Boffe S, Remacle J, Toussaint O (2005) Repeated exposure of human skin fibroblasts to UVB at subcytotoxic level triggers premature senescence through the TGF-betal signaling pathway. J Cell Sci 118:743-758

Fisher NC, Tutt A, Sim E, Scarpello JH, Green JR (1996)Collagenous colitis responsive to octreotide therapy. J Clin Gastroenterol 23: 300-301

Ju HK, Cho EJ, Jang MH, Lee YY, Hong SS, Park JH, Kwon SW (2009) Characterization of increased phenolic compounds from fermented Bokbunja (RubuscoreanusMiq.) and related antioxidant activity. J Pharm Biomed Anal 49: 820-827

Kerrigan JJ, Mansell JP, Sandy JR (2000) Matrix turnover. J Orthod 27: 227 233

Kim J, Lee CW, Kim EK, Lee SJ, Park NH, Kim HS, Kim HK, Char K, Jang YP, Kim JW (2011) Inhibition effect of Gynuraprocumbens extract on
UV-B-induced matrix-metalloproteinase expression in human dermal fibroblasts. J Ethnopharmacol 137: 427-433

Lee CH, Liu SY, Lin MH, Chiang WF, Chen TC, Huang WT, Chou DS, Chiu CT, Liu YC (2008) Upregulation of matrix metalloproteinase-1 (MMP1) expression in oral carcinomas of betel quid (BQ) users: roles of $B Q$ ingredients in the acceleration of tumour cell motility through MMP-1. Arch Oral Biol 53: 810-818

Pourrat A, Pourrat H, Potier P (1973) On the composition of Poterium spinosum L. (Rosaceae). Ann Pharm Fr 31: 321-324

Shin JS, Cho EJ, Choi HE, Seo JH, An HJ, Park HJ, Cho YW, Lee KT (2014) Anti-inflammatory effect of a standardized triterpenoid-rich fraction isolated from Rubuscoreanus on dextran sodium sulfate-induced acute colitis in mice and LPS-induced macrophages. J Ethnopharmacol 158: 291-300

Tsuji N, Moriwaki S, Suzuki Y, Takema Y, Imokawa G (2001) The role of elastases secreted by fibroblasts in wrinkle formation: implication through selective inhibition of elastase activity. Photochem Photobiol 74: 283-290

Tsukahara K, Takema Y, Moriwaki S, Tsuji N, Suzuki Y, Fujimura T, Imokawa G (2001) Selective inhibition of skin fibroblast elastase elicits a concentration-dependent prevention of ultraviolet B-induced wrinkle formation. J Invest Dermatol 117:671-677

Varani J, Perone P, Fligiel SE, Fisher GJ, Voorhees JJ (2002)Inhibition of type I procollagen production in photodamage: correlation between presence of high molecular weight collagen fragments and reduced procollagen synthesis. J Invest Dermatol 119: 122-129

Visse R, Nagase H (2003)Matrix metalloproteinases and tissue inhibitors of metalloproteinases: structure, function, and biochemistry. Circ Res 92: 827-839 